\title{
Temperature Dependent Mechanical Properties of Natural and Synthetic Rubber in Practical Structures
}

\author{
Samiul Kaiser ${ }^{1}$, Reza Rabbani ${ }^{2}$, Reaz Ahmed ${ }^{2}$ and Salim Kaiser ${ }^{3, *}$ \\ Department of Civil Engineering, Bangladesh University of Engineering and Technology, Dhaka-1000, Bangladesh \\ Department of Mechanical Engineering, Bangladesh University of Engineering and Technology, Dhaka-1000, Bangladesh \\ Directorate of Advisory, Extension and Research Services, Bangladesh University of Engineering and Technology, Dhaka-1000, Bangladesh
}

\begin{abstract}
In this proposal the mechanical properties of natural and synthetic rubbers are studied under different temperatures both real and ageing heat treatment conditions. For this purpose, tire rubber and bearing pad rubber are considered as they are most governed in natural and synthetic rubber respectively. The experimental results confirm that the impact of real temperature is higher on the mechanical properties than that of ageing temperature because of ambient temperature aggravate thermal motion and changes the molecular arrangement of rubber other than the ageing samples recovers the mechanical properties during breezy. Except hardness, all the cases in terms of mechanical properties like tensile strength, elongation, Young's modulus and Poisson's ratio of bearing pad rubber provide the higher performance than the tire rubber. Under ageing treatment condition the degraded mechanical properties recover well by the natural rubber since extremely ordered long chain of the molecular structure. The significant differences in the micrographs of the two rubbers suggest that tire rubber consists of uniform grains because of its highly controlled molecular arrangement. Under heat treatment the microstructure turned rougher and the size of the voids became larger as temperature increases the secondary cross linking reaction which initiate to cracks.
\end{abstract}

Keywords: rubbers; heat treatment; mechanical properties; microstructure

\section{Introduction}

Rubber is an important engineering material. Mainly two types of rubbers natural and synthetic rubber are generally used in numerous industrial and household applications [1]. Natural rubber one kind of polymer that is derived from a tree named Hevea brasiliensis as naturally occurs in the plant cells. It mainly contains the cis-1, 4-isoprene as well as trace impurities like proteins and dirt [2,3]. On the other hand, synthetic rubber is a man-made polymer synthesised from various petroleumbased precursors like crude oil by using polymerization technique under controlled conditions. The most commonly available synthetic rubber material is styrenebutadiene, synthesized from the copolymerization of styrene and 1, 3-butadiene [4, 5]. A lot of applications are offered the natural rubber, including tires, rubber gaskets, vibration isolators, shock mounts, electrical components, hoses and tubes, and drive couplings, etc. Natural rubbers moreover have good physical strength and flexibility but lower oil resistance. Synthetic rubber is used for different rubber crop, depending on the diversity of exclusive properties namely earthquake rubber bearings, conveyor belts, car bumpers, solar panel heat collectors, mechanical vibrators, radiators, synthetic leather, electrical insulation, moulds etc. Usually, when comparing the properties 
of natural rubber, synthetic rubbers offer many advantages, such as better resistance to aging and weathering and suitability for use in environments exposed to chemicals, oils and greases, oxidizing compounds, high temperatures, and other extreme conditions [6-8].

Rubber materials face to high heat, abrasion, dynamic fatigue and destructive chemicals, a lot of agent being there in the surroundings takes part in damage to rubber. More over degradation by ozone, oxygen, light and other causes the rubber discolour and cracking which initiate to early failure $[9,10]$. Both natural and synthetic rubber requires age resisters for best performance. Protection against oxygen and ozone attack as well as heat and light damage are conferred by antioxidants, antiozonates, ultraviolet light protectors and waxes $[11,12]$. Damage to rubber by abrasion is combated by the incorporation of fillers like carbon black. Such mechanical and chemical damages limit their original functions and can be a serious issue in terms of safety hazards when both the natural and synthetic rubber is used. The resistance to both high pressure and temperature is a serious technological challenge in such field, since it is difficult to improve significantly both properties [13-15].

From the literature it is known that the rubbers have to face different level of working temperature. It can be steady or for a short period of time. Amorphous polymers have a random molecular structure that does not have a sharp melting point. Instead, amorphous material softens gradually as temperature rises. These materials are more sensitive to stress failure due to the presence of hydrocarbons. Present study is mainly associated with the examining of temperature dependent mechanical properties of natural and synthetic rubber. To make the study two following types of rubber has been considered as natural rubber is dominant in tire rubber and synthetic rubber is dominant in bearing pad rubber.

\section{Materials and methods}

The current study was associated with the materials akin to commercial tire and bearing pad rubber. The chemical composition of the rubbers is tabulated bellow in Table 1.

An electrical muffle furnace was used for ageing treatment of the tire and bearing pad rubber at various temperatures. A freeze also used for the
Table 1: Chemical composition of the tire and bearing pad rubber (wt \%).

\begin{tabular}{|l|l|l|}
\hline Composition & Tire & Bearing pad \\
\hline Natural Rubber & 27 & - \\
\hline Synthetic Rubber & 13 & 58 \\
\hline Carbon Black & 27 & 30 \\
\hline Steel & 15 & - \\
\hline Magnesium oxide & - & 5 \\
\hline Zincoxide & 2 & 2 \\
\hline Fillers & 16 & - \\
\hline Accelerator (TMT) & - & 1.5 \\
\hline MBT (curing agent) & - & 1.5 \\
\hline Sulphur & - & 1.5 \\
\hline Aromatic Oil & - & 0.5 \\
\hline
\end{tabular}

ageing treatment at below the room temperature. In course of ageing treatment the rubber samples were heated at desire temperature for one hour followed by naturally cooled at room temperature. The samples of $15 \times 15 \times 5 \mathrm{~mm}$ were cut from tire and bearing pad rubber for hardness measurement. Hardness of heated rubber samples at various states was measured in Durometer Hardness tester. The hardness of the aged samples was performed at room temperature. Other than the real temperature the rubber was heated on a steel plate into the furnace and the hardness measurement was conducted closes the furnace door to maintain the real temperature. For the mechanical study tensile test sample was perpetrated following ASTM Standard D415. The gauge length, width and thickness were 30, 6 and $4 \mathrm{~mm}$ respectively. For the real temperature testing of Young's modulus and Poisson's ratios a temperature control perplex box size of $200 \times 250 \times 300 \mathrm{~mm}$ was prepared. The temperature control sensor was used for controlling the temperature and a heater as well as ice pieces were used to get the required temperature. Ultimate tensile strength and the elongation at break at real time temperature were measured with the help of temperature controlled Instron 3369 Universal Testing Machine ranging from 0 to $250^{\circ} \mathrm{C}$ at a strain rate of $0.1 / \mathrm{s}$. But aged samples were tested with this machine at room temperature. An average of seven consistent readings was accepted as the representative properties of each rubber.

Microstructural observation of the worn 
specimens was done carefully by using an USB digital camera attached to PC and some preferred photomicrographs were taken. The SEM investigation was conducted by using a Link AN-10000 JEOL scanning electron microscope.

\section{Results and Discussion}

\subsection{Hardness}

Figure 1 shows the effect of real and ageing temperature on the hardness of natural rubber and synthetic rubber namely tire and bearing pad rubber respectively. In general, this type of materials has an inverse relationship between temperature and hardness $[16,17]$. For real temperature both the tire and bearing pad rubbers have a significant loss in hardness with increasing the temperature. With increasing temperature material becomes soft and resistance to compressive force is decreased as consequence hardness decreases. At the lower temperature the rubber turns out to be harder, stiffer as we as fewer resilient. These are associated with the decrease in free volume between adjacent molecules and a consequent decrease in the mobility. The stability at high temperatures is related to the chemical structure and the formation of chemical cross-linking bonds of the elastomer. Low temperature crystallization causes stiffening, but is easily reversed by warming [18].

From the graphs displayed the hardness decrease with increasing ageing temperature for both the samples. But the rate of decreasing is quite lower than real time temperatures. In course of ageing treatment rubber material recover some properties when the rubber materials are permitted to accomplish at room temperature. However, the hardness of tire rubber is slightly greater than bearing pad rubber in all temperatures due to presents of steel particles and other filler materials as represented in the table 1 . Although the decreasing rate of hardness is higher for the tire rubber. Despite the poor heat aging properties of natural rubber, but the rubber components subject to high stress, the natural rubber so far is still considered almost indispensable material. The reason for this dilemma is that the typical molecular structure of this historic material. Natural rubber is a highly ordered long chain molecular structure guarantees its excellent flexibility, but the unsaturated bonds of the polymer main chain to make it easier and heat gradually incidence of secondary cross linking reaction $[19,20]$. (a)

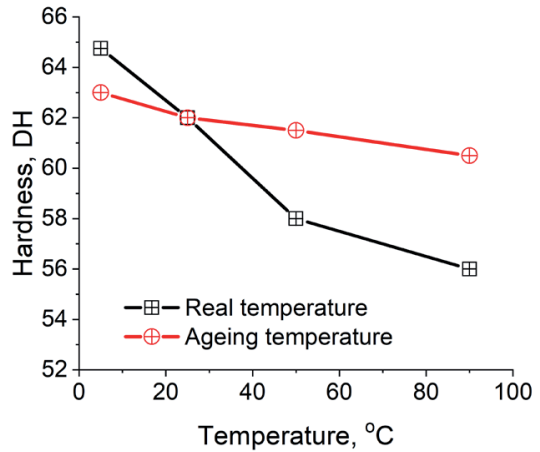

(b)

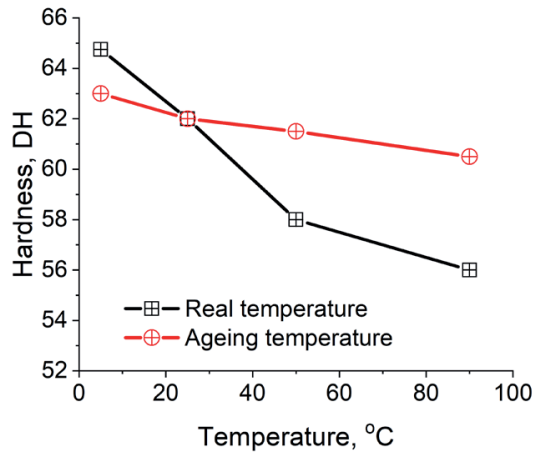

Figure 1: Experimental result of hardness under different heat treatment of $(a)$ tire and $(b)$ bearing pad rubber

\subsection{Mechanical properties}

\subsubsection{Tensile strength}

The variation of ultimate tensile strength of tire and bearing pad rubber at different real and ageing temperatures are shown in Fig. 2, where the bearing pad rubber shows about three times of the strength of the tire rubber. The bearing pad rubber is selfreinforcing rubber so it has high tensile strength. The molecular structure of this neoprene rubber is regular and the molecular chain contains the polarity of chlorine atoms. The group increases the force between the molecules. Therefore, under the action of an external force, it is easy to stretch the crystal and the molecules are not easily slipped. Presence of $\mathrm{MgO}$ and $\mathrm{ZnO}$ like nanoparticles into the bearing pad rubber exhibit remarkable reactivity as a catalyst and act as filler. Mineral sulphur is a widely used ingredient to form cross-links between the rubber chains. In addition, the molecular weight is large, so the tensile strength is large $[21,22]$.

The tensile properties of tire and bearing pad rubbers are similar in nature under different heat treatment but differ in intensity. The tensile strength of rubber decreases with incensement of temperature. However, there is a high rate of strength loss at real 
temperatures for both the rubbers. During ageing the strength recovered by the rubber samples causes the lower variation of strength. The incensement of ambient temperature exacerbates thermal motion, which changes the arrangement of rubber molecular chain. With the effect of external forces, rubber molecular chain is easier to move in the stress direction and harder to rehabilitate. The temperature is lowered, the crystallization rate is increased, the rubber is hardened after crystallization, and the tensile stress is increased. Due to the regularity and polarity of the molecular structure, the greater cohesion of the neoprene limits the thermal motion of the molecules, especially at low temperatures. It is also difficult to restore the original shape after the tensile deformation, that is, the crystallization occurs, the rubber loses its elasticity, and even the brittle fracture phenomenon occurs, so the chloroprene rubber has poor cold resistance. During the earlier stages of heat ageing, crosslink scissions and the formation of new crosslinks into the stable networks affected these properties [23].

(a)

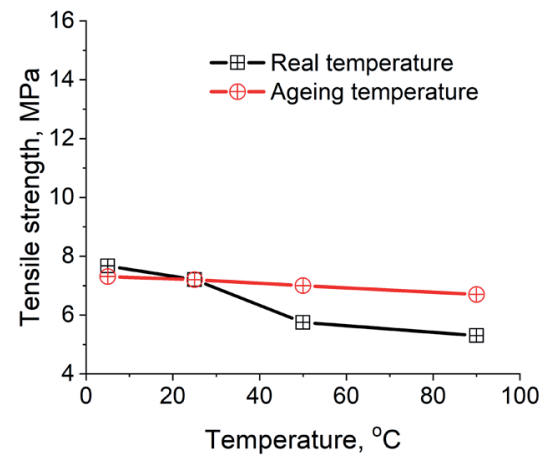

(b)

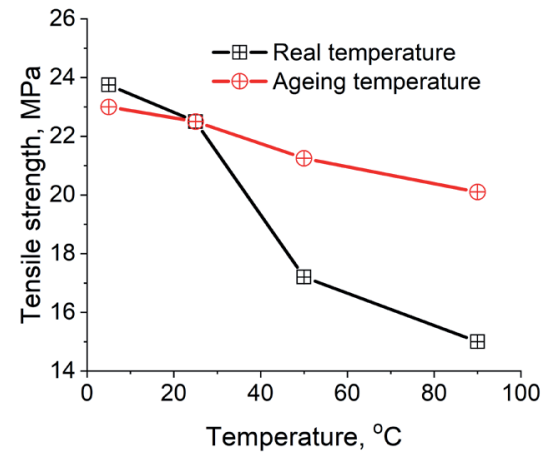

Figure 2: Variation of tensile strength with temperature for (a) tire and $(b)$ bearing pad rubber

\subsubsection{Percentage of elongation}

The experimental results of elongation at break of tire rubber under both real and ageing temperatures are plotted in Fig. 3a. The same for bearing pad rubber also plotted in Fig. 3b. At room temperature the elongation of bearing pad rubber is about five times higher than that of tire rubber. From the table 1 it is shown that the bearing pad rubber filled by about $58 \%$ of synthetic rubber. The percentages of the elongation of these rubber materials directly associated to the molecules bond, formation of crosslinking density, and the quantity of synthetic rubber into natural rubber. The chlorine atom attached to the double bond of the molecular chain of the neoprene rubber makes more elastic [22]. In addition, additives, fillers, softeners, and sulphur are added to accelerate the vulcanization process which influences the charge of elongation at break.

(a)

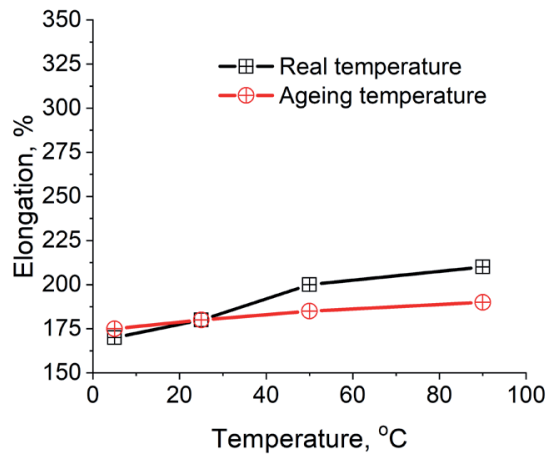

(b)

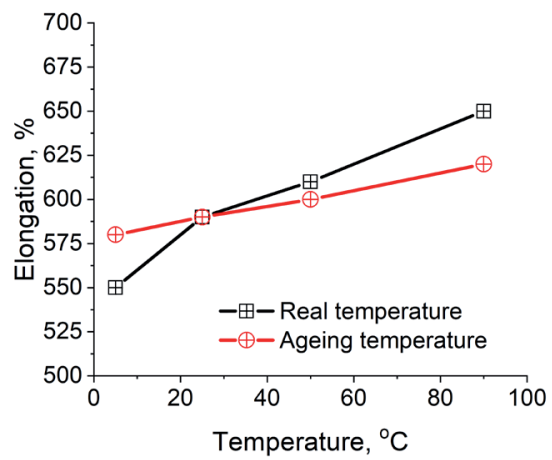

Figure 3: Variation of elongation of braking with temperature for (a) tire and (b) bearing pad rubber

The percentages of elongation at break give higher result with the increase in temperature. In general, the reaction occurs more rapidly while the temperature is raised. When the reaction rate is high distribution of the curative compounds reaches at form within natural rubber [24]. The effect of addition of polyvinylpyrrolidone agent acts as plasticizer that increases elasticity to the natural rubber. The chlorine 
atom attached to the double bond of the molecular chain of the neoprene rubber makes both the double bond and the chlorine atom inactive, so the storage stability of the vulcanized rubber is good; it is not easily affected by heat, oxygen and light in the atmosphere. Its aging resistance, especially weather resistance and ozone resistance, is second only to ethylene propylene rubber and butyl rubber in general rubber, far superior to natural rubber.

\subsubsection{Young's modulus}

The graphical presentation in Figure 4, Young's modulus of the experimental rubbers decreases through increasing for both the real and ageing temperature. But the real temperature effect is more pronouns. This phenomenon is quite easy to describe. With increasing of temperature rubber material becomes soft and quite easy to deform it. So at high temperature it is easier to deform with minimum load. As material becomes less stiff at lower temperature, young modulus decreases. Another phenomenon is observed that at all temperatures young modulus of tire rubber is greater than bearing pad rubber since the tire rubber is stiffer than bearing pad rubber. That means, bearing pad rubber deforms easily than tire rubber with same load as shown earlier. Mainly rubbers or elastomers are composed of one or more monomers polymerized to form a polymer. The extensibility of rubbers can be reduced by cross linking. In this process, the random coils are tied or cross linked to others at intervals randomly along their length. This can be achieved by reaction with added chemicals. As seen young modulus of tire rubber is higher than bearing pad rubber so cross linking is much more in tire rubber than bearing pad rubber. In case of ageing temperature treatment, the deviations both tire and bearing pad rubber are low because of recovery behaviour of the rubber materials. The higher recovery property makes the lower deviation for bearing pad rubber [11, 22].

\subsubsection{Poisson's ratio}

The Poisson's ratios of the experimental rubbers at real and ageing temperature are displayed in Figure 5, those were calculated from the experimental data. The graphs demonstrate that with increasing both the temperatures Poisson's ratio increases of the rubbers. With increasing temperature material becomes soft and both lateral and longitudinal strain increased but as Poisson's ratio is increased so (a)

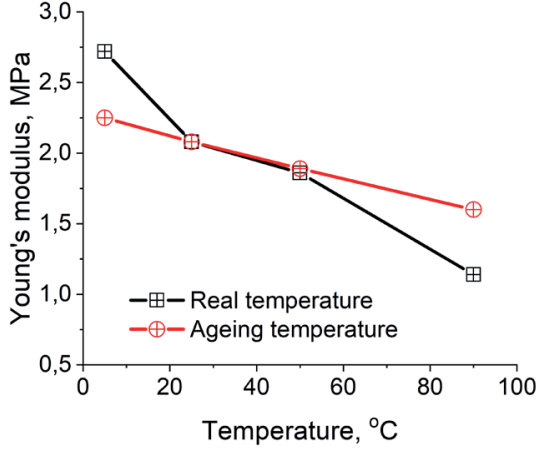

(b)

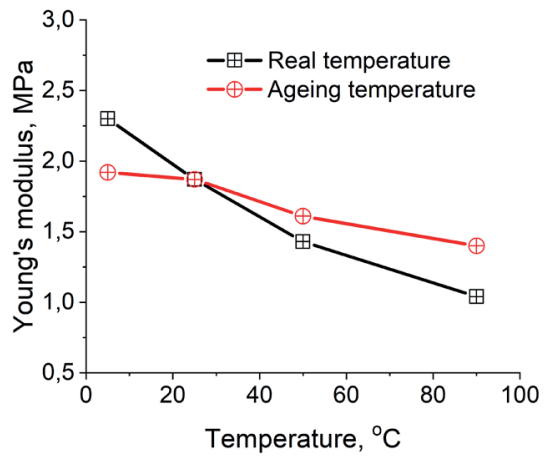

Figure 4: Variation of Young's modulus with temperature for (a) tire and (b) bearing pad rubber

(a)

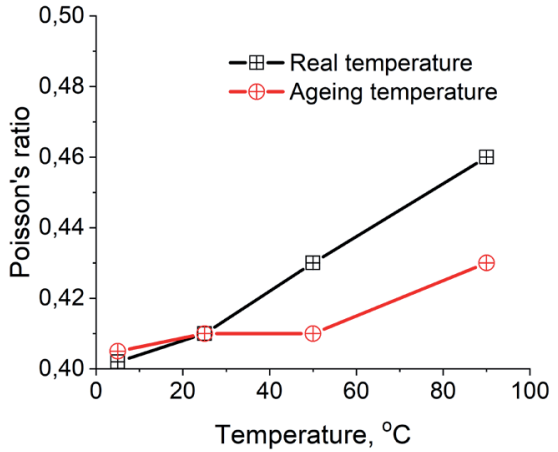

(b)

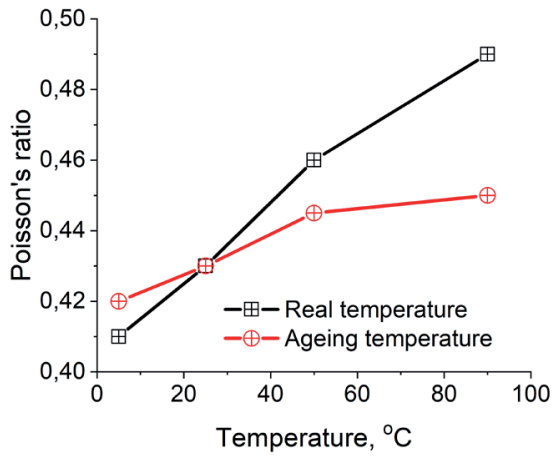

Figure 5: Variation of Poisson's ratio with temperature for (a) tire and (b) bearing pad rubber 
lateral strain change is dominant over longitudinal strain. One more phenomena are observed from the graphs that bearing pad rubber Poisson's ratio is always to some extent greater than that of tire rubber. Like real time temperatures Poisson's ratio also increases with ageing temperatures but the intensity is lower of both the rubbers. That means lateral strain change is lower which dominant over longitudinal strain as the aged samples recover some extend of the mechanical behaviour. In another word it may be clarify aged samples relatively shows the lower elongation because of it recuperate the properties in coarse of ageing treatment. Similar natures of higher values of Poisson's ratios are observed for bearing pad rubber because of the higher elongation of bearing pad rubber $[25,26]$.

\subsection{Optical microscopic observation}

Figure 6 and Figure 7 show the microstructure of the experimental tire rubber and bearing pad rubber under both real and ageing heat treatment conditions at various levels. The microstructural image of natural rubber real temperature at $5^{\circ} \mathrm{C}$ consists of uniform grains because of tire rubber contends the highly ordered long chain molecular structure [27]. It clearly shows that the surface has a small dot due to presence of additive like antioxidant, vulcanizing agent etc., which indicates that all ingredients homogenously distributed in the rubber matrices. Furthermore, the image at aged conditions at the same temperature shows the recrystallized grains with uniform distribution of the filler and other agents. It is because of at room temperature movement these elements distributed uniformly during recrystallization. Ageing at room temperature as well as real temperature at $25^{\circ} \mathrm{C}$ the microstructure displays the different foreign particles as its fast cooling during manufacturing. At higher heating temperature these particles are more pronoun. High temperature ageing sample consists of different cracks because of shrinkage of the material coarse of ageing treatment cooling to room temperature. In contrast, synthetic rubber shows the needle shapes fillers homogenously dispersed and adhered perfectly to the matrix. This might be due to the good processing parameter and latex compounding method that allowed the palygorskite to reinforce the adjacent matrix and enhanced physical and mechanical properties. At the high temperature treatment it obviously shows

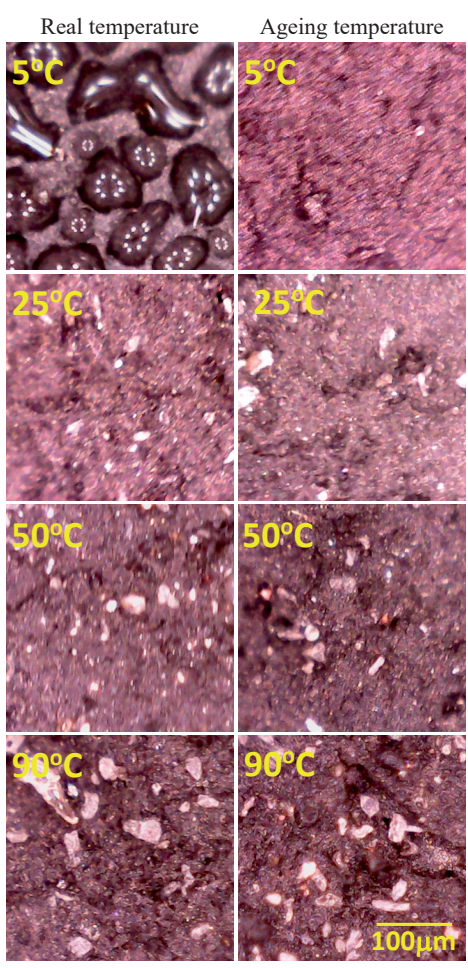

Figure 6: Optical micrograph of tire rubber under different heat treatment

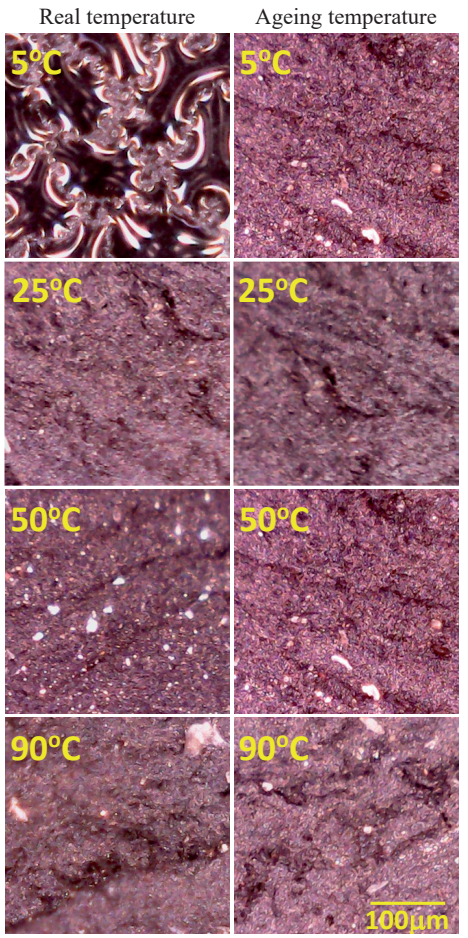

Figure 7: Optical micrograph of bearing pad rubber under different heat treatment 
the presence of many tear lines on the fracture surface. It was proven that the composite needed a high energy to break the chain and it was designated the effect of better interaction between chains and has higher strength properties. Furthermore, the uniform tear lines in one direction presence on the tire rubber [21].

The morphology changes on the surface of samples before and after thermal ageing apparently, the surface of the tire rubber was relatively homogeneous and smooth with no obvious defects. After heat treatment for higher temperature, the surface of tire rubber turned rougher and the size of the voids became larger, but the size of the voids was relatively small. Due to the regularity and polarity of the molecular structure of bearing pad rubber limits the thermal motion of the molecules and difficult to restore the original shape [28].

\subsection{SEM observation}

Figure 8 exhibits the typical SEM micrographs of the tire rubber and bearing pad rubber as received condition. The microstructure of tire rubber shows the fine grains with uniformly distributed different particles in the matrix. This type of natural rubber consists of different filler materials having a highly ordered molecular structure. On the other hand, the micrograph of bearing pad rubber shows significant differences by showing the coarse grains in the matrix. The microstructure also confirms the presence of some cracks or voids. During vulcanizing increases the secondary cross linking reaction which initiate to cracks. Bearing pad rubber is usually cured with oxide of zinc, magnesium and lead for improving the quality of rubber [29, 30]. From the figure it can be seen that the spread of filler is evenly distributed, due to the good interaction between the filler and rubber. This indicates that rubber and filler interactions improved mechanical properties. Empty cavities occur due to presence of silica, a hydroxyl group that helps hydrogen bond with silica molecules or other elements. These are polar and do not show a de-adhesion phenomenon that occurs at the interface of the filler and natural rubber matrix [31].
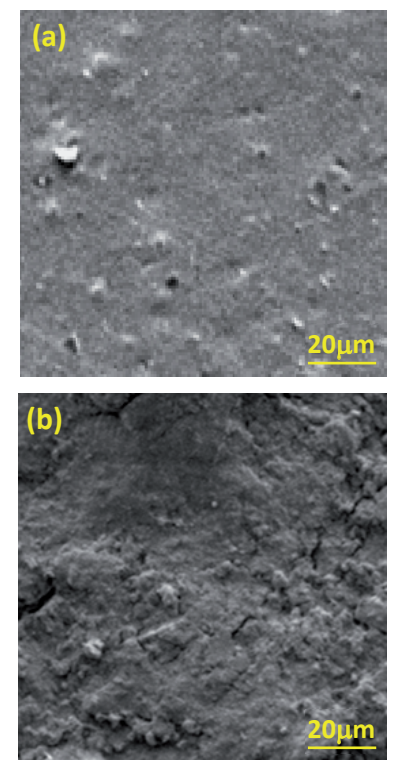

Figure 8: SEM micrographs of the (a) tire rubber and (b) bearing pad rubber

\section{Conclusions}

The results of this study related to natural and synthetic rubber subjected to heat treatment can be summarized as

The hardness of tire rubber is relatively higher than bearing pad rubber under all heat treatment conditions because the tire rubber generally contents steel particles as well as other filler materials. The hardness of both the rubbers degrades significantly with increasing the real temperature as the material becomes soft and decrease the resistance to compressive force. During ageing the strength recovered by the rubber samples causes the lower variation of strength than that of real temperatures.

Rubber materials losses the tensile strength with incensement of real temperature and the elongation at break increases. Ambient temperature exacerbates thermal motion, which changes the arrangement of rubber molecular chain. With the effect of external forces, rubber molecular chain is easier to move in the stress direction and harder to rehabilitate. Neoprene has a good balance of properties, including good chemical stability and usefulness over a wide temperature range.

Young's modulus of tire rubber is always greater than bearing pad rubber at different real time temperatures and ageing temperature condition as tire rubber is stiffer than bearing pad rubber. 
Poisson's ratios increase with temperatures means lateral strain change is lower which dominant over longitudinal strain having higher values for bearing pad rubber.

Experimental tire rubber is a highly ordered long chain molecular structure and bearing pad rubber contents the regularity and polarity of the molecular structure, the greater cohesion of the neoprene limits the thermal motion of the molecules. As a result, the tire rubber recovers its strength more under ageing heat treatment.

Owing highly ordered molecular structure uniform grains are in attendance into to the tire rubber. The microstructure turned rougher and the size of the voids became larger when elevated temperature is increased. It is also hoist the secondary cross linking reaction which initiate to cracks.

\section{Acknowledgments}

\section{The authors would like to convey their profound gratitude to DAERS office of Bangladesh University of Engineering and Technology, Dhaka for assisting the experiment.}

\section{References and Notes}

1. Hu, B., Zhou, Y., Luo, M. C., Wei Y. C., Liu G. X, Liao, S., Zhao, Y. (2021) Influence of I-quebrachitol on the properties of centrifuged natural rubber, e-Polymers, vol. 21, no. 1, pp. 420427, https://doi.org/10.1515/epoly-2021-0042.

2. Pethrick, R. A., (1989) Acoustical Properties, Comprehensive Polymer Science and Supplements, vol. 2, pp. 571-599, https://doi.org/10.1016/B978-0-08-096701-1.00054-9.

3. Men, X., Wang, F., Chen, G. Q., Zhang, H. B., Xian, M. (2019) Biosynthesis of Natural Rubber: Current State and Perspectives, International Journal of Molecular Sciences, vol. 20, no. 50, pp. 1-22, doi:10.3390/ijms20010050.

4. Blackley, D. C. (1983) Synthetic Rubbers: Their Chemistry and Technology, 1st edition, Springer, Dordrecht, Netherlands, https://doi.org/10.1007/978-94-009-6619-2.

5. Kan, T., Strezov, V., Evans, T. (2017) Fuel production from pyrolysis of natural and synthetic rubbers, Fuel, vol. 191, pp. 403-410, https://doi.org/10.1016/j.fuel.2016.11.100.

6. Samsuri, A. (2010) Degradation of natural rubber and synthetic elastomers, Shreir's Corrosion, vol. 3, pp. 2407-2438, .https://doi.org/10.1016/B978-044452787-5.00117-7.

7. Gent, A. N. (2012) Engineering with Rubber, 3rd edition, Hanser Publishers, Ohio, USA.

8. Kapitonov, E. A., Petrova, N. N., Mukhin, V. V., Nikiforov, L. A., Gogolev, V. D., Shim, E. L., Okhlopkova A. A., Cho, J. H. (2021) Enhanced physical and mechanical properties of ni- trile-butadiene rubber composites with n-cetylpyridinium bromide-carbon black, Molecules, vol. 26, no. 805, pp. 1-7, https://doi.org/10.3390/molecules26040805.

9. Cantu, Y. V., Hauge, R., Norman, L., Billups, W. E. (2003) Enhancement of the chemical resistance of nitrile rubber by direct fluorination, Journal of Applied Polymer Science, vol. 89, pp. 971-979. https://doi.org/10.1002/app.12212.

10. Baudet, C., Grandidier, J. C., Cangemi, L. (2011) A damage model for the blistering of polyvinylidene fluoride subjected to carbon dioxide decompression, Journal of the Mechanics and Physics of Solids, vol. 59, pp. 1909-1926, https:// doi.org/10.1016/j.jmps.2011.04.010.

11. Carpenedo, G. A., Demori, R., Carli, L. N., Giovanela, M., Paoli, M. A. D., Crespo, J. S. (2020) Evaluation of stabilizing additives content in the mechanical properties of elastomeric compositions subject to environmental and accelerated aging, Materials Research, vol. 23, no. 5, pp. 1-9, https://doi. org/10.1590/1980-5373-MR-2020-0139.

12. Shah, A. A., Hasan, F., Shah, Z., Kanwal, N., Zeb, S. (2013) Biodegradation of natural and synthetic rubbers: A review, International Biodeterioration and Biodegradation, vol. 83, pp. 145-147, http://dx.doi.org/10.1016/j.ibiod.2013.05.004

13. Valentini, L., Manchado, M. A. L., (2018) Rubber nanocomposites for extreme environments: Critics and Counterintuitive Solutions Frontiers in Materials, vol. 5, no. 49, pp. 1-5, https://doi.org/10.3389/fmats.2018.00049.

14. Kaiser, S., Kaiser, M. S., Ahmed, S. R. (2019) Comparison of wear behaviour of commercial tire and bearing pad rubber under dry sliding condition, Journal of Sustainable Structures and Materials, vol. 2, no. 2, pp. 1-12, https://doi. org/10.26392/SSM.2019.02.02.001.

15. Robertson, C. G., Hardman, N. J. (2021) Nature of carbon black reinforcement of rubber: Perspective on the Original Polymer Nanocomposite, Polymers, vol. 13, no. 538, pp. 1-28, https://doi.org/10.3390/polym13040538.

16. Sun, J. T., Sun, J. J., Zhang, P. (2013) Effects of the interaction of hardness, resilience, and fatigue properties on the abrasion properties of rubber blends, Journal of Applied Polymer Science, vol. 130, no. 2, pp. 1212-1219, https://doi. org/10.1002/app.39258.

17. Kaiser, S., Kaiser, M. S., Ahmed, S. R. (2020) Wear behavior of commercial tire rubber against mild steel in dry, wet and $3.5 \% \mathrm{NaCl}$ corrosive environment, Journal of Energy, Mechanical, Material, and Manufacturing Engineering. vol. 5, no. 1, pp. 1-10, https://doi.org/10.22219/jemmme. v5i1.10428

18. Esmaeil, E. R. T., Vahidifar, A., Esmizadeh, E., Rodrigue, D. (2021) Chemistry, processing, properties, and applications of rubber foams, Polymers, vol. 13, no. 1565, pp. 1-53, https://doi.org/10.3390/polym13101565 
19. Mrpra (1989) Comparison of natural and synthetic rubbers, Materials and Design, vol. 10, pp. 39-41, https://doi. org/10.1016/0261-3069(89)90035-6.

20. Bueche, F. (1958) Mechanical properties of natural and synthetic rubbers, Rubber Chemistry and Technology, vol. 31, no. 1, pp. 1-18, https://doi.org/10.5254/1.3542259.

21. Arayapranee, W., Rempel, G. L. (2013) Effects of polarity on the filler-rubber interaction and properties of silica filled grafted natural rubber composites, Journal of Polymers, vol. 2013, pp. 1-9, http://dx.doi.org/10.1155/2013/279529.

22. Morton, M. (1999) Rubber Technology, 3rd edition, Springer, Dordrecht, Netherlands, https://doi.org/10.1007/978-94017-2925-3

23. Sheridan, M. F. (2010) Rubber handbook, 14th edition, R. T. Vanderbilt Company Inc., Norwalk, USA.

24. Milani, G., Leroy, E., Milani, F., Deterre, R., (2013) Mechanistic modeling of reversion phenomenon in sulphur cured natural rubber vulcanization kinetics, Polymer Testing, vol. 32, no. 6, pp. 1052-1063, https://doi.org/10.1016/j.polymertesting.2013.06.002.

25. Robertson, C. G., Bogoslovov, R., Roland, C. M. (2007) Effect of structural arrest on Poisson's ratio in nanoreinforced elastomers, Physical Review E, vol. 75, no. 5, pp. 1-7, https://doi. org/10.1103/PhysRevE.75.051403.

26. Bouaziz, R., Truffault, L., Borisov, R., Ovalle, C., Laiarinandrasana, L., Garnier, G. M., Fayolle, B. (2020) Elastic Properties of Polychloroprene Rubbers in Tension and Compression during Ageing, Polymers, vol. 12, no. 2354, pp. 1-14, https://doi. org/10.3390/polym12102354.

27. Mandal, A., Pan, S., Mukherjee, S., Saha, A. K., Thomas, S., Sengupta, A., (2014) Variations in Specific Heat and Microstructure in Natural Rubber Filled with Different Fillers as Studied by Differential Scanning Calorimetry, Journal of Polymer and Biopolymer Physics Chemistry, vol. 2, no. 1, 25 28, https://doi.org/10.12691/jpbpc-2-1-4.

28. Yeh, M. H., Hwang, W. S., Cheng, L. R. (2007) Microstructure and mechanical properties of neoprene-montmorillonite nanocomposites, Applied Surface Science, vol. 253, no. 10, pp. 4777-4781, http://dx.doi.org/10.1016/j.apsusc.2006.10.064.

29. Candau, N., Oguz, O., Albiter, N. L., Forster, G., Maspoch, M. L. (2021) Poly (Lactic Acid)/Ground Tire Rubber Blends Using Peroxide Vulcanization, Polymers, vol. 13, no. 1496, pp. 1-20, https://doi.org/10.3390/polym13091496.

30. Colom, X., Genesca, M. M., Mujal, R., Formela, K., Cañavate, J. (2018) Structural and physico-mechanical properties of natural rubber/GTR composites devulcanized by microwaves: Influence of GTR source and irradiation time, Journal of Composite Materials, vol. 52, no. 22, pp. 3099-3108, https:// doi.org/10.1177/0021998318761554.
31. Nurdin, B., Erna, F. (2013) The effect zeolite addition in natural rubber polypropylene composite on mechanical, structure, and thermal characteristics, Makara Journal of Technology, vol. 17, no. 3, pp. 113-130, https://doi.org/10.7454/ mst.v17i3.2926. 